\title{
FORMULACIÓN DE GRÁNULOS BASES PARA LA INCORPORACIÓN DE INGREDIENTES ACTIVOS CON EFECTO BIOLÓGICO SOBRE EL HONGO SIMBIÓTICO CULTIVADO POR LAS HORMIGAS FORRAJERAS DEL GÉNERO Atta ${ }^{1}$
}

\author{
Ena Edith Herrera ${ }^{2 / *}$, Vera Sánchez, ${ }^{* *}$ Helga Blanco ${ }^{* * *}$ \\ Palabras clave: Atta spp., hormigas forrajeras, formulación de gránulos, control biológico, hongo simbiótico. \\ Keywords: Atta spp., leaf cutting ants, granular formulations, biological control, symbiotic fungi.
}

Recibido: $26 / 11 / 12$

\section{RESUMEN}

Las hormigas forrajeras (Atta spp.) pueden destruir plantaciones completas de hortalizas y de otras plantas de importancia económica en América Tropical y Subtropical. Cortan el tejido de las plantas y lo transportan a nidos subterráneos, donde cultivan un hongo del Phylum basidiomycota, que es su alimento principal. En la actualidad, no se cuenta con una estrategia efectiva de manejo de esta plaga. La mayoría de productos disponibles comercialmente son muy poco efectivos, dejan residuos en el ambiente $\mathrm{y}$ tienen un precio alto para los pequeños agricultores. La presente investigación se propuso evaluar diferentes ingredientes en la preparación de granulados que presenten alto nivel de acarreo y potencial para la incorporación de ingredientes activos con efecto biológico contra el hongo simbiótico que cultivan las hormigas forrajeras. Se prepararon gránulos con diferentes combinaciones y concentraciones de excipientes o coadyuvantes. Además se evaluó citropulpa, extracto alcohólico de cáscaras de naranja y aceite de semillas de naranja, como atrayentes.

1 Este trabajo forma parte de la tesis de maestría de la primera autora en Agricultura Ecológica, CATIE, Turrialba, Costa Rica. Proyecto: Desarrollo de productos alternativos para el manejo ecológico del hongo simbiótico y único alimento de las hormigas cortadoras (zompopas), FORINVES (FV-004-07).
Aceptado: 06/05/13

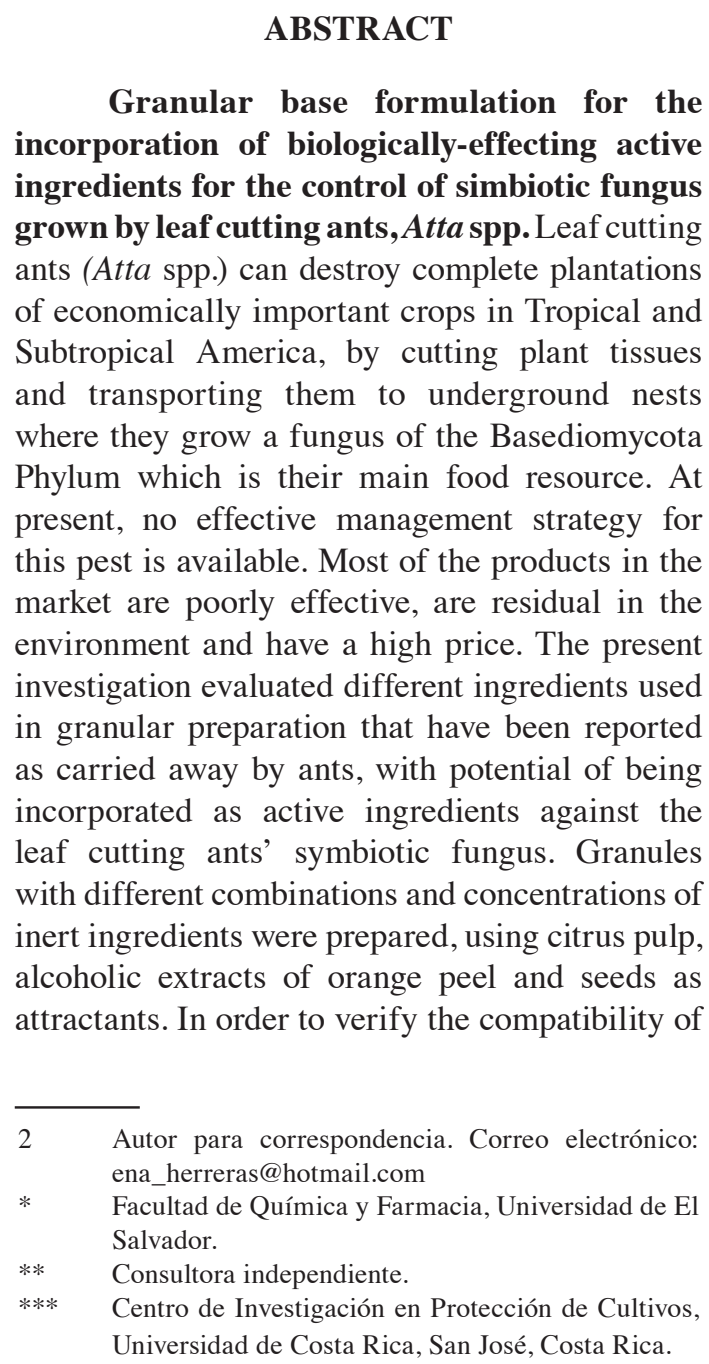

\section{ABSTRACT} incorporation of biologically-effecting active ingredients for the control of simbiotic fungus grown by leaf cutting ants, Atta spp. Leaf cutting ants (Atta spp.) can destroy complete plantations of economically important crops in Tropical and Subtropical America, by cutting plant tissues and transporting them to underground nests where they grow a fungus of the Basediomycota Phylum which is their main food resource. At present, no effective management strategy for this pest is available. Most of the products in the market are poorly effective, are residual in the environment and have a high price. The present investigation evaluated different ingredients used in granular preparation that have been reported as carried away by ants, with potential of being incorporated as active ingredients against the leaf cutting ants' symbiotic fungus. Granules inert ingredients were prepared, using citrus pulp, alcoholic extracts of orange peel and seeds as attractants. In order to verify the compatibility of Universidad de Costa Rica, San José, Costa Rica. 
A los mejores formulados se incorporó extracto de Azadirachta indica (neem), 3 cepas de Trichoderma spp., y levaduras en diferentes concentraciones, para comprobar la compatibilidad de las formulaciones con ingredientes activos. Se evaluó diferentes características de los gránulos como indicadores de viabilidad y estabilidad del formulado. Se encontró que los cebos formulados con citropulpa son capaces de mantener estable la acidez y, además, conservan la viabilidad de Trichoderma spp., y levaduras por más tiempo que los formulados elaborados con extracto alcohólico de cáscaras de naranja como atrayente. Además, el gránulo base con citropulpa presentó un costo de producción más bajo. Se concluye que el formulado con citropulpa como atrayente es una base apropiada para la incorporación de ingredientes activos con efecto biológico contra el hongo simbiótico y tiene potencial como base para un producto comercial.

\section{INTRODUCCIÓN}

Las hormigas forrajeras son originarias de Sudamérica donde han evolucionado con su ambiente natural desde hace millones de años hasta el punto de considerarse los insectos más evolucionados y exitosos. Debido a su herbivoría generalista, se considera que su efecto ecológico en los ecosistemas es equivalente al de los grandes herbívoros (Holldobler y Wilson 1990). En los bosques tropicales consumen entre el 12 y el $17 \%$ de las hojas producidas y causan importantes pérdidas económicas en la agricultura, ya que son capaces de destruir plantaciones completas, que representan especial peligro para hortalizas y plantas jóvenes de árboles frutales, forestales y ornamentales de América Tropical y Subtropical (Ricci et ál. 2005). Las hormigas forrajeras usan el tejido que cortan de las plantas para cultivar un hongo que es su principal alimento. Con este hongo, las hormigas mantienen una relación simbiótica muy compleja producto de la co-evolución, que pertenece a la Familia the base formulations with the active ingredients, Azadirachta indica (neem), Trichoderma spp., and yeasts were used in different concentrations. Granule characteristics were evaluated as indicators of viability and stability of formulates. Baits formulated with citrus pulp were capable of keeping a stable acidity, and also to conserve Trichoderma spp., and yeasts viability for a longer period than formulates containing alcoholic extract of orange peel used as an attractant. Also, granules with a citrus pulp base had a lower production cost. It was concluded that citrus pulp is an appropriate base for the incorporation of active ingredients with biologic effect against the symbiotic fungi and has potential as a base for commercial production.

Lepiotaceae dentro de la tribu Leucocoprineae y el Pilum Basidiomycota (Kumar et ál. 2006, Chapela et ál. 1994, Hinkle et ál. 1994).

Desde 1900 se han probado diversas técnicas y productos para el manejo de esta plaga, donde los más aplicados fueron productos químicos sintéticos (Pérez 1947). El dodecacloro, conocido comercialmente como Mirex, fue un producto eficiente para el control de hormigas forrajeras, pero se retiró del mercado por su persistencia en el suelo, alto potencial de movilidad ambiental y su capacidad de acumularse progresivamente en la cadena alimenticia (ATSDR 1995). En la actualidad, la mayoría de los ingredientes activos disponibles comercialmente, entre ellos sulfluramida, fipronil, clorpirifos y aldrín, no proporcionan resultados efectivos a largo plazo, son residuales en el ambiente y tienen un precio poco accesible para los pequeños agricultores (Varón 2006). El control biológico del insecto y el hongo simbiótico se ha considerado como alternativa de manejo por su menor daño ambiental. 
Como control biológico del hongo simbiótico se han evaluado antagonistas, extractos y otros metabolitos vegetales mezclados con atrayentes, en la mayoría de los casos como cebos que se colocan en los caminos de las hormigas. Sin embargo, en la mayoría de los casos, no se ha considerado la estabilidad química ni biológica del formulado en el tiempo y por lo tanto no han tenido la visión clara de ofrecer al mercado un producto alternativo eficiente para el manejo de esta plaga (Caffarini et ál. 2008, Caffarini et ál. 2006, Varón 2006, Gruber y Valdix 2003, Palacios y Glandstone 2003, Naccarata y Jaffe 1989).

Los cebos son una forma de presentación de plaguicidas, creados para atraer plagas y provocarles la muerte. Entre las ventajas de los cebos, se consideran su especificidad, la aplicación localizada, el poco impacto ambiental y el bajo costo económico. En la composición de cebos granulados generalmente se incluyen 3 tipos de sustancias: ingredientes activos, atrayentes, y excipientes o ingredientes inertes (Caffarini et ál. 2006, Varón 2006, Naccarata y Jaffe 1989). El atrayente debe ser apropiadamente seleccionado para asegurarse que el ingrediente activo pueda ejercer su acción sobre la plaga. Las pulpas o aceites esenciales de diferentes especies cítricas, hojuelas de avena, germen de trigo, harinas y aceites de diferentes leguminosas se han informado como buenos atrayentes de hormigas forrajeras (Arango y Sinigui 2008, Caffarini et ál. 2008, Caffarini et ál. 2006, Varón 2006, López y Orduz 2003, Palacios y Glanstone 2003). Los excipientes o ingredientes inertes sirven para facilitar la acción de los ingredientes activos y favorecen la consistencia, forma y estabilidad de la formulación.

Para asegurar la calidad y la seguridad de la aplicación y el impacto ambiental de formulados como los cebos, se deben realizar pruebas fisicoquímicas y toxicológicas (OMS-FAO 2004). Para formulados que contienen productos derivados de animales, plantas, bacterias y ciertos tipos de minerales, se recomienda realizar pruebas fisicoquímicas y biológicas, como el porcentaje de humedad, rango de acidez $(\mathrm{pH})$, concentración o número de conidios, viabilidad, eficacia y estabilidad (Mazariegos 2003). El contenido de agua es importante para prevenir la degradación del formulado y garantizar la estabilidad en almacenamiento. Conocer la acidez $(\mathrm{pH})$ permite prever el riesgo de descomposición de los ingredientes activos, el deterioro de las características físicas y el posible deterioro del envase contenedor del formulado. En el caso de antagonistas como ingredientes activos, es muy importante garantizar la eficacia biológica del producto mediante la concentración y viabilidad de las estructuras reproductivas por gramo de formulado; la viabilidad se puede evaluar mediante el porcentaje de germinación de las estructuras reproductivas (OMS-FAO 2004). Para garantizar las propiedades del formulado en el tiempo o estabilidad durante el almacenamiento, se pueden evaluar sus características físicas y biológicas en tiempo real y en condiciones similares de temperatura, humedad relativa y luz a las que tendría en el mercado, o se puede someter a un procedimiento de almacenamiento acelerado, al combinar temperaturas altas y diferentes periodos. No obstante, no existen métodos estandarizados para realizar el ensayo de estabilidad acelerada de formulados biológicos (OMS-FAO 2004).

La presente investigación se propuso evaluar diferentes ingredientes en la preparación de formulados granulares y seleccionar los gránulos que fueran más rápidamente acarreados por las hormigas forrajeras hasta sus nidos y que además fueran estables físicamente y que permitieran la incorporación de ingredientes activos con efecto biológico contra el hongo simbiótico cultivado por las hormigas forrajeras.

\section{MATERIALES Y MÉTODOS}

La investigación se realizó en el año 2009, en los laboratorios y el campus del Centro Agronómico Tropical de Investigación y Enseñanza (CATIE), ubicado en el cantón Turrialba de la provincia de Cartago, Costa Rica, localizado a $9^{\circ} 52^{\prime}$ Norte y $83^{\circ} 38^{\prime}$ ' Oeste, a una altura de 602 $\mathrm{msnm}$, con un rango de temperatura que oscila 
entre los 22 y $28^{\circ} \mathrm{C}$, con precipitación promedio anual de $2600 \mathrm{~mm}$ y $87 \%$ de humedad relativa.

\section{Formulación de gránulos base}

Para la formulación de los gránulos base se consideraron diferentes materias primas y otros ingredientes de fácil adquisición en el mercado y de bajo costo. Se seleccionaron como atrayentes citropulpa, aceite esencial de semillas de naranja y extracto alcohólico de cáscaras de naranja y como coadyuvantes se usó azúcar pulverizada, maicena, avena, carboximetilcelulosa, gelatina, talco, bentonita, aceite de soya y agua en diferentes proporciones. El aceite esencial de semillas de naranja y el extracto alcohólico de cáscaras en investigaciones anteriores realizadas en CATIE; mostraron ser buenos atrayentes para las hormigas, incluidas las forrajeras. La citropulpa se había utilizado en el laboratorio de patología de CATIE, en pruebas preliminares y se observó que favorece la dureza y consistencia del gránulo, además es un producto disponible en el mercado local. El azúcar y la maicena también ayudan a la dureza del gránulo. Además, el azúcar puede ser un atrayente adicional. La avena se ha utilizado como atrayente para la elaboración de cebos artesanales para el manejo de hormigas forrajeras (Arango y Sinigui 2008, Varón 2006). La carboximetilcelulosa y la gelatina actúan como aglutinantes y el talco como deslizante pues evita que los polvos se adhieran a las paredes del equipo granulador. La bentonita es un material de soporte y le aporta dureza al gránulo. La función del aceite de soya es como atrayente y proporciona una leve propiedad hidrofóbica al gránulo. El agua se usa para darle humedad a las mezclas y para aglutinar los polvos.

Con los ingredientes anteriores, se formularon un total de 24 diferentes gránulos base; 13 con citropulpa, 5 con aceite esencial semillas de naranja y 6 con extracto alcohólico de cáscaras de naranja como atrayentes. Para cada formulado, los ingredientes se mezclaron hasta obtener una masa levemente húmeda que se colocó sobre la bandeja alimentadora del equipo granulador, con el fin de obtener gránulos tubulares de aproximadamente $0,25 \mathrm{~cm}$ de diámetro y de longitud variable. Los formuladores que permitieron la formación de gránulos tubulares se secaron a $30 \pm 2^{\circ} \mathrm{C}$ durante $72 \mathrm{~h}$, y se rotó cada día para lograr un secado homogéneo y se fragmentaron hasta un largo no mayor de un centímetro. De los 24 formulados se seleccionaron 6 que presentaron las mejores características en cuanto a forma, consistencia dureza y resistencia a la hidratación (Figura 1): 3 elaboradas con citropulpa y 3 con aceite esencial de semillas de naranja. Con estos gránulos (Cuadro 1) se realizó la prueba de preferencia de acarreo en campo y las determinaciones de porcentaje de humedad y acidez $(\mathrm{pH})$.

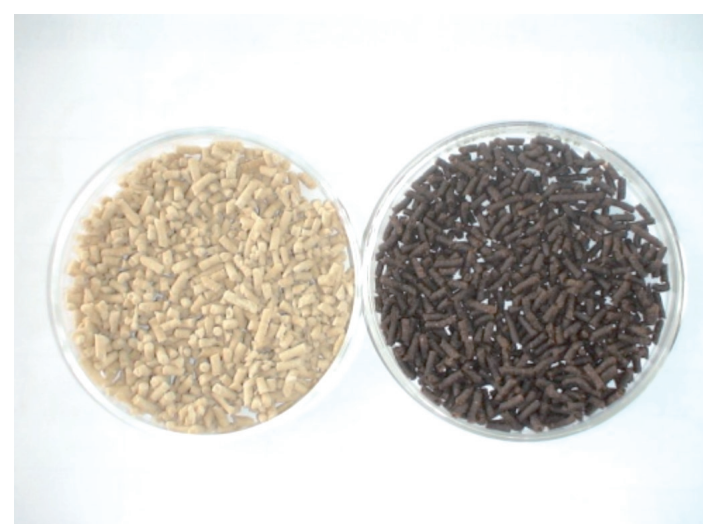

Fig. 1. Muestra del tamaño y forma de los gránulos seleccionados, a la izquierda gránulos con aceite esencial de semillas de naranja y a la derecha granulos preparados con citropulpa. 
Cuadro. 1 Gránulos base seleccionados para la evaluación de porcentaje de humedad y acidez (pH) y para la prueba de acarreo.

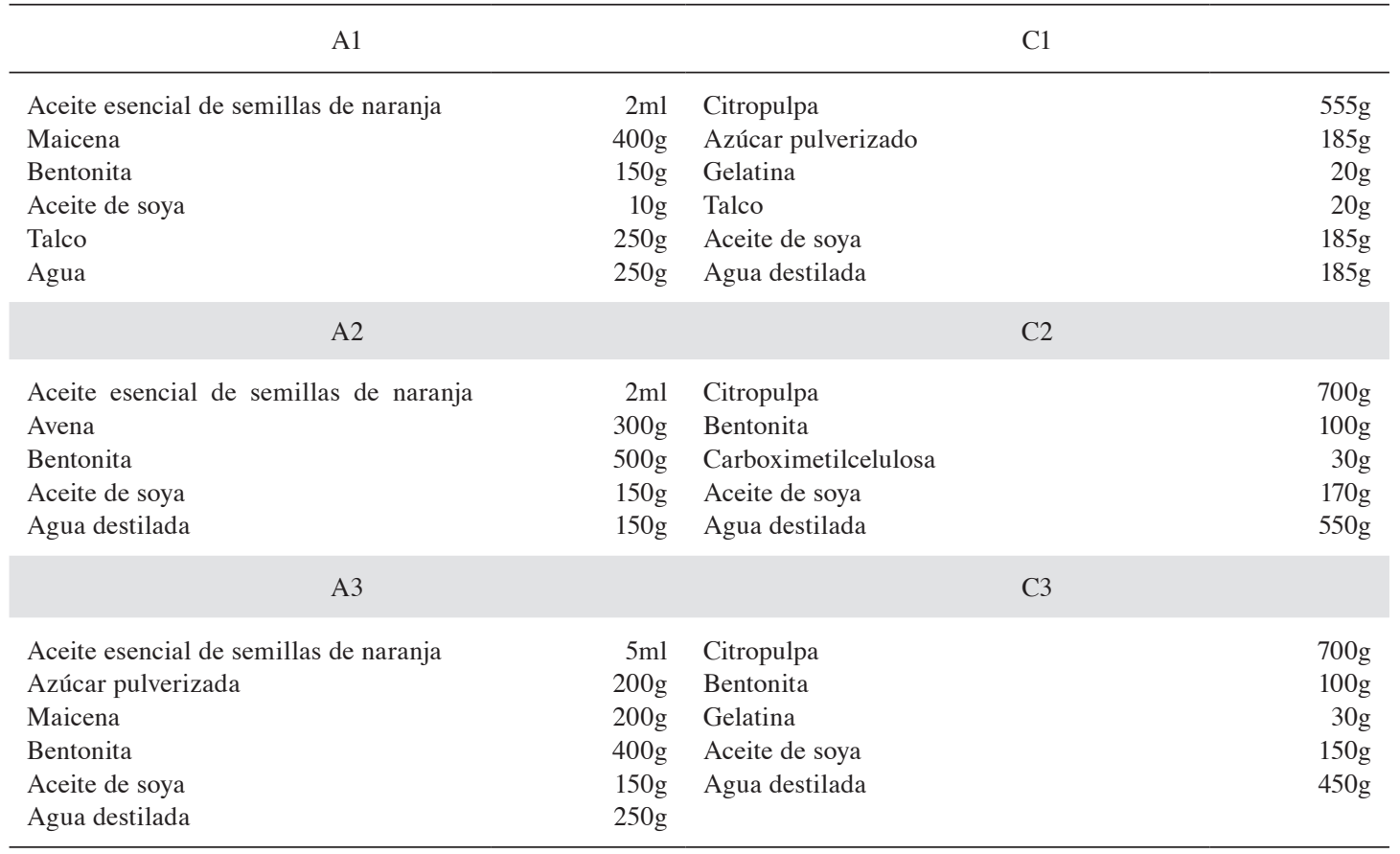

\section{Evaluación de humedad y acidez de los gránulos base}

Para determinar el porcentaje de humedad se pesó $1,00 \mathrm{~g}$ de cada formulado y por diferencia de peso se obtuvo la pérdida de humedad después de ser sometido a una temperatura de $150^{\circ} \mathrm{C}$ hasta peso constante, se hicieron 3 determinaciones por muestra.

La acidez se midió en una suspensión de 10 g de cada formulado y $25 \mathrm{ml}$ de agua destilada libre de dióxido de carbono (dilución 1 en 2,5) a $25^{\circ} \mathrm{C}$, se leyó el valor de $\mathrm{pH}$ directamente en el potenciómetro. La medición se hizo 4 veces por muestra.

\section{Evaluación de la preferencia de acarreo de los gránulos base}

La preferencia de acarreo se midió como la rapidez (minutos) con que las hormigas forrajeras acarearon los gránulos al nido. Se ubicaron 4 nidos y se seleccionaron 10 caminos que mostraron forrajeo activo, en cada camino se colocaron muestras de cada formulado y un testigo. Las muestras se colocaron en cajitas plásticas a $50 \mathrm{~cm}$ de la entrada al nido, en cada cajita se colocó $1,00 \mathrm{~g}$ de gránulos. Como testigo de tiempo de acarreo se usó sulfluramida con el nombre comercial de Mirex- $\mathrm{S}_{\circledast}$, dado que plaguicida fue desarrollado con efecto atrayente hacia estas hormigas. Se colocaron 7 cajitas plásticas separadas por $10 \mathrm{~cm}$ (4 al lado derecho y 3 al lado izquierdo) en cada camino activo, 6 con los formulados y una con el testigo (Figura 2).

En el ensayo se usó un diseño de bloques completamente aleatorizados con 10 repeticiones (caminos). Se midió el tiempo en minutos que las hormigas tardaron en sacar todos los gránulos del formulado de la caja para ser llevados dentro del nido (modificación del método propuesto por Delabie et ál. 2000). A los datos obtenidos se les analizó la varianza (ANAVA) con el programa de estadística Infostat versión 2009 (Di Rienzo et ál. 2009). 


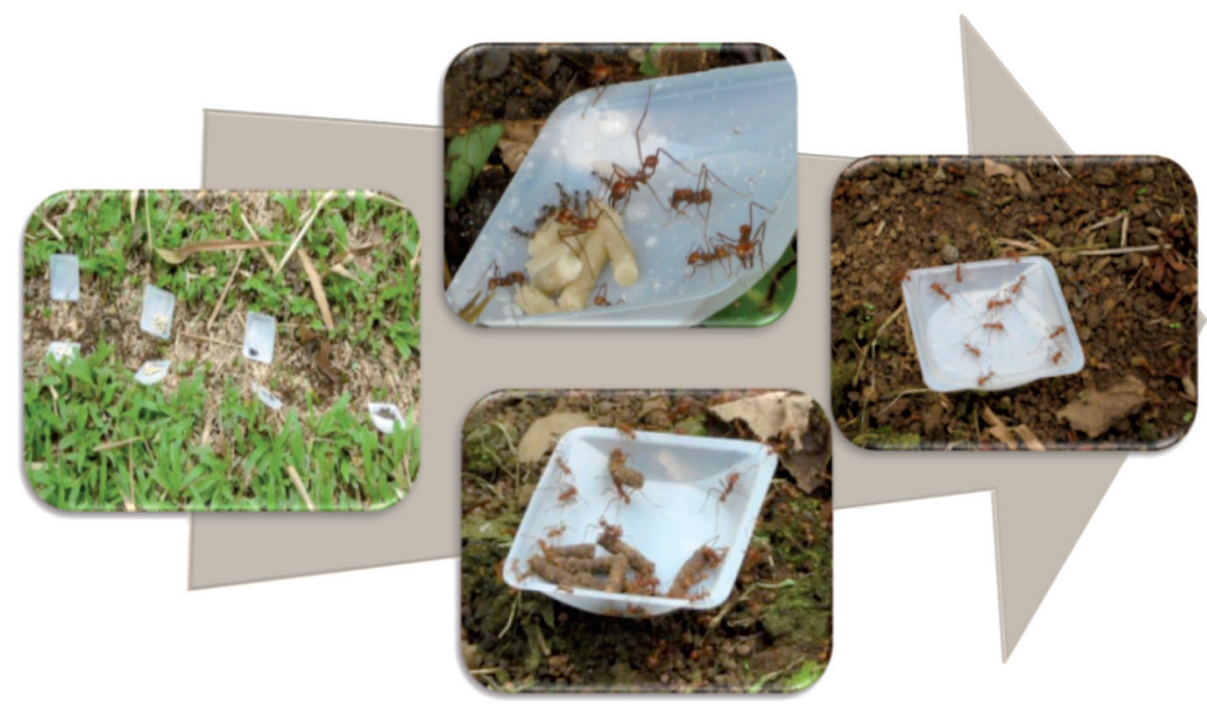

Fig. 2. Secuencia de imágenes de la prueba de preferencia acarreo, se observa la colocación de los gránulos en el camino de acarreo y los recipientes vacíos de los formulados que contaron con la aceptación de las hormigas forrajeras.

\section{Evaluación del extracto alcohólico de cáscaras de naranja como sustituto del atrayente del aceite de semillas de naranja en el formulado A1}

La etapa anterior permitió seleccionar un formulado con aceite de semillas de naranja (A3) y un preparado con citropulpa (C1). Sin embargo, debido a escasez en el mercado local del aceite de semillas de naranja, se decidió evaluar el efecto atrayente del extracto alcohólico de cáscaras de naranja, para usarlo en el formulado A1 (Cuadro 1). Se prepararon 2 formulados 2 gránulos B1 y B2, a los que se les sustituyó el atrayente extracto alcohólico de cáscaras de naranja, al $2 \%$ y al $3 \%$, respectivamente y se les corrigió el volumen de agua. Se hicieron varias pruebas de forma y tamaño de los gránulos y se evaluó la preferencia de acarreo en 5 caminos (repeticiones) con forrajeo activo de hormigas género Atta. En esta prueba se comparó la rapidez de acarreo de los gránulos B1 y B2 de la fórmula original con atrayente aceite de semillas de naranja (A3).

\section{Formulación de gránulos base con diferentes ingredientes activos}

Con base en los resultados anteriores se seleccionaron 2 formulados granulares base $\mathrm{B}$ y C (Cuadro 2) para evaluar la incorporación de ingredientes activos.

Se elaboraron un total de 16 granulados con 3 ingredientes (Cuadro 3), 4 con Trichoderma spp., 6 con levaduras para hacer pan (Saccharomyces cerevisiae) y 6 con extracto de Azadirachta indica (neem). Se usó una mezcla de 3 cepas de Trichoderma spp., proporcionadas por el laboratorio de patología del CATIE; las 3 cepas mostraron antagonismo contra el hongo simbiótico de las hormigas, pero no entre ellas, al ser evaluadas in vitro. La levaduras y el extracto de $A$. indica utilizados, son productos disponibles en el mercado local con los nombre de Saf instant y Triact 64 EC, respectivamente (Cuadro 3). Los ingredientes activos se adicionaron al formulado con el agua correspondiente a la fórmula para evitar el exceso de humedad para lograr un mezcla uniforme. En el caso de las cepas de Trichoderma spp., se mezcló la 
Cuadro 2. Formulas base evaluadas con ingredientes activos, con extracto alcohólico de cáscaras de naranja (B) o citropulpa (C) como atrayentes.

\begin{tabular}{ll|ll}
\hline \multicolumn{1}{c|}{ B } & \multicolumn{2}{c}{ C } \\
\hline Extrato alcohólico de naranjas & $30 \mathrm{ml}$ & Citropulpa & $555 \mathrm{~g}$ \\
Azúcar pulverizada & $200 \mathrm{~g}$ & Azúcar pulverizado & $185 \mathrm{~g}$ \\
Maicena & $200 \mathrm{~g}$ & Gelatina & $20 \mathrm{~g}$ \\
Bentonita & $400 \mathrm{~g}$ & Talco & $20 \mathrm{~g}$ \\
Aceite de soya & $150 \mathrm{~g}$ & Aceite de soya & $185 \mathrm{~g}$ \\
Agua destilada & $175 \mathrm{~g}$ & Agua destilada & $185 \mathrm{~g}$ \\
\hline
\end{tabular}

Cuadro 3. Formulados granulados que se prepararon con diferentes concentraciones de ingredientes activos (Trichoderma spp., levaduras y Neem) y 2 atrayentes diferentes: citropulpa (C) y extracto alcohólico de cáscaras de naranja (B).

\begin{tabular}{|c|c|c|c|}
\hline Código & Atrayente & Ingrediente activo & Concentración del ingrediente activo \\
\hline $\mathrm{CTr} 2,34 \times 10^{7}$ & \multirow{2}{*}{$\mathrm{C}$} & \multirow{4}{*}{ Trichoderma spp. } & $2,34 \times 10^{7}$ \\
\hline $\mathrm{C} \operatorname{Tr} 7,01 \times 10^{7}$ & & & $7,01 \times 10^{7}$ \\
\hline $\mathrm{BTr} 2,34 \times 10^{7}$ & \multirow{2}{*}{ B } & & $2,34 \times 10^{7}$ \\
\hline $\mathrm{B} \operatorname{Tr} 7,01 \times 10^{7}$ & & & $7,01 \times 10^{7}$ \\
\hline CL 5,0\% & \multirow{3}{*}{$\mathrm{C}$} & \multirow{3}{*}{ Levaduras } & $5,0 \%$ \\
\hline CL $10,0 \%$ & & & $10,0 \%$ \\
\hline CL $20,0 \%$ & & & $20,0 \%$ \\
\hline BL 5,0\% & \multirow{3}{*}{ B } & \multirow{3}{*}{ Levaduras } & $5,0 \%$ \\
\hline BL $10,0 \%$ & & & $10,0 \%$ \\
\hline BL 20,0\% & & & $20,0 \%$ \\
\hline BN $0,4 \%$ & \multirow{3}{*}{ B } & \multirow{3}{*}{ Neem } & $0,4 \%$ \\
\hline BN $0,6 \%$ & & & $0,6 \%$ \\
\hline BN $1,0 \%$ & & & $1,0 \%$ \\
\hline $\mathrm{CN} 0,4 \%$ & \multirow{3}{*}{$\mathrm{C}$} & \multirow{3}{*}{ Neem } & $0,4 \%$ \\
\hline $\mathrm{CN} 0,6 \%$ & & & $0,6 \%$ \\
\hline CN $1,0 \%$ & & & $1,0 \%$ \\
\hline BT & Testigo $^{1}$ & - & - \\
\hline CT & Testigo $^{2}$ & - & - \\
\hline Mirex- $\mathrm{S}_{\circledast}$ & Testigo $^{3}$ & - & - \\
\hline
\end{tabular}

Testigos 1 y 2 del formulado sin ingrediente activo, testigo 3: granulado comercial.

cantidad de esporas (polvo) de cada cepa en forma proporcional para obtener una concentración de aproximadamente a $10^{7}$ esporas por gramo de formulado y a los gránulos terminados se les hizo conteo de esporas. La levadura y el neem se agregaron en las cantidades necesarias para obtener concentraciones de 1 y 2 por ciento en los gránulos.
Evaluación del porcentaje de humedad, porcentaje de absorción de humedad en campo, acidez y estabilidad de los gránulos formulados con diferentes ingredientes activos

Para estas pruebas se seleccionaran 6 granulados: uno de cada ingrediente activo por cada formulado base: $\mathrm{B} \operatorname{Tr} 7,01 \times 10^{7}, \mathrm{C} \operatorname{Tr} 7, \mathrm{BN} 1 \%$, 
BL5\%, CN1\% y CL5\%; junto con los formulados base sin ingrediente activo (BT y CT) y el granulado comercial: sulfluramida (Mirex- $\mathrm{S}_{\circledast}$ ) como testigos. El porcentaje de humedad y acidez se determinaron a través de las metodologías antes descritas, en los gránulos recién preparados y en gránulos que se dejaron a temperatura ambiente en un lugar fresco y seco durante 9. Para determinar el porcentaje de absorción de humedad en el campo se colocaron 30 g de cada gránulos en platos Petri sin tapa directamente sobre el suelo. Se hicieron 2 repeticiones, cada repetición se hizo en un camino activo de forraje diferente, los tratamientos se colocaron en fila de 9 platos completamente al azar, separados por $15 \mathrm{~cm}$. Los platos de la primera y segunda repetición se recolectaron 2 y 4 h después de ser colocados, respectivamente, para determinar el porcentaje de humedad, por diferencia de peso. Para estimar la estabilidad de los cebos en el tiempo, se pesó en bolsas plásticas blancas, $100 \mathrm{~g}$ de cada cebo granulado y se almacenaron a temperatura ambiente en un lugar fresco y seco durante 9 semanas. Transcurrido ese tiempo se les hizo análisis de humedad, acidez, concentración o número de conidios y viabilidad según metodologías antes descritas (OMS-FAO 2004).

\section{Evaluación del porcentaje de concentración y viabilidad de los gránulos formulados con microorganismo como ingredientes activos}

Antes de realizar estas pruebas los gránulos se dejaron a temperatura ambiente en un lugar fresco y seco durante 9 semanas. A los granulados con Trichoderma spp., como ingrediente activo se le hicieron análisis de concentración de conidios y viabilidad, como conidias germinadas. La concentración de conidios se determinó en una suspensión de $1,00 \mathrm{~g}$ de formulado pulverizado en $9 \mathrm{ml}$ de agua destilada estéril, se tomó una muestra de la suspensión y se contó la cantidad de presentes mediante un hematocímetro (cámara de Neubauer). Se realizaron conteos de más de 100 esporas, para disminuir el error por variabilidad (Pariona et ál. 2007) y se consideraron 4 datos por muestra.

Para determinar la viabilidad se consideró la cantidad de esporas germinadas Trichoderma spp. Se preparó una suspensión de 1,00 g del grano pulverizado de gránulos en $9 \mathrm{ml}$ de agua destilada estéril que se dejo en incubación a $26^{\circ} \mathrm{C}$. Se tomó una muestra de la suspensión y se contó la cantidad de conidias germinadas por gramo, en un hematocímetro (cámara de Neubauer). Se realizaron los conteos de las esporas germinadas a las 24,48 y 72 h después de preparada la suspensión; el conteo se hizo 4 veces por gránulo.

En el caso de los formulados con levaduras, tanto para el análisis de la concentración como la viabilidad, se hizo un conteo de unidades formadoras de colonias (ufc) en placas con medio de cultivo agar papa dextrosa (PDA). Los platos se inocularon con $0,2 \mathrm{ml}$ de una suspensión $10^{2}$, preparada con $1,00 \mathrm{~g}$ del polvo del gránulo, y se incubaron a $26^{\circ} \mathrm{C}$. Se contó número de unidades formadoras de colonias a las $48 \mathrm{~h}$ después de inocular las placas (Modificación método propuesto por Mazariegos 2003). Este análisis se hizo 3 por gránulo.

\section{Evaluación de la preferencia de acarreo de gránulos formulados con diferentes ingredientes activos}

La preferencia de las hormigas por los gránulos se evaluó como rapidez de acarreo (minutos). Los 16 cebos granulados (Cuadro 3), se evaluaron en 3 ensayos, cada ensayo incluyó un ingrediente activo y sus concentraciones y el granulado comercial (Mirex- $\mathrm{S}_{\circledast}$ ), según la metodología antes descrita para los gránulos base (sin ingrediente activo). Se utilizó el diseño de bloques completamente al azar con 10 repeticiones (caminos de acarreo). Los datos obtenidos se examinaron mediante el análisis de varianza (ANAVA) por medio del programa de estadística Infostat versión 2009 (Di Rienzo et ál. 2009). De esta prueba se seleccionaron los 6 cebos que presentaron mayor rapidez de acarreo.

Para el análisis de costos parciales se consideraron los precios de los materiales usados en los formulados B y C a la fecha del presente estudio, cotizadas en un supermercado local. Además se uso el precio de mercado de los ingredientes activos y el granulado comercial. El costo se calculó para un kilogramo de los formulados. No se incluyen los costos asociados a mano de obra, ni 
a los servicios de energía eléctrica y agua, dado que los gránulos se prepararon a pequeña escala y únicamente para fines experimentales.

\section{RESULTADOS Y DISCUSIÓN}

\section{Humedad y acidez de gránulos base}

El rango de porcentaje de humedad de los gránulos presentó un rango muy amplio, de 4,01 a $18,10 \%$ (Cuadro 4).

Cuadro 4. Porcentaje de humedad y acidez $(\mathrm{pH})$ de los formulados base.

\begin{tabular}{ccc}
\hline Gránulo & \% Humedad & $\mathrm{pH}$ Promedio \\
\hline C1 & 18,10 & 3,8 \\
C2 & 10,29 & 3,7 \\
C3 & 7,46 & 3,7 \\
A1 & 4,01 & 4,4 \\
A2 & 8,38 & 3,8 \\
A3 & 7,84 & 4,7 \\
\hline
\end{tabular}

C: formulaciones con citropulpa como atrayente y A: con aceite de semillas de naranja.

Aunque no existen límites establecidos para prevenir la degradación de formulados bioplaguidas y garantizar la estabilidad en almacenamiento, la OMS-FAO (2004) señala que para gránulos de larvicidas bacterianos el contenido de agua no debe exceder el 5\% (gramos agua/ gramos formulados).

La acidez de los 6 gránulos evaluados, en general fue alta (Cuadro 4), sin embargo, los gránulos $\mathrm{C} 1, \mathrm{C} 2$ y $\mathrm{C} 3$ presentaron el $\mathrm{pH}$ más bajo; esto podría explicarse por el aporte de acidez que pudo proporcionar citropulpa que fue el componente que se uso en mayor cantidad en estos gránulos (555 g, Cuadro 2). Por lo tanto es importante que en futuras investigaciones se considere la acidez de los ingredientes antes de incorporarlos a los formulados, principalmente en el caso de ingredientes que no sean estables a pH ácidos.

\section{Preferencia de acarreo de los gránulos base}

Los análisis mostraron diferencias en el tiempo de acarreo entre los formulados base con citropulpa (C1, C2 y C3) y los otros formulados evaluados (Cuadro 5), pero no presentaron diferencias estadísticas significativas entre sí. La citropulpa fue buen atrayente para las hormigas, tanto cuando se usó $555 \mathrm{~g}(\mathrm{C} 1)$ o $700 \mathrm{~g}(\mathrm{C} 2 \mathrm{y}$ C3) (Cuadro 1) e independiente de los otros componentes de cada formulado, lo que permite suponer que es la citropulpa la que tiene el efecto más importante. En el caso de los formulados con aceite de semillas de naranja como atrayente, únicamente el A1 se pudo incluir en el análisis, dado que los formulados A2 y A3 no fueron acarreados por las hormigas al nido durante el tiempo que consideró la investigación. Sin embargo, el A1 no mostró diferencia estadística significativa respecto a la sulfluramida (Mirex-S $\mathrm{S}_{\circledast}$ ). Por lo tanto, los formulados con citropulpa fueron los mejores en cuanto a la rapidez con que fueron llevados por las hormigas al nido. Según Boaretto y Forti 1997, el pH ligeramente ácido y el contenido de carbohidratos, nitrógeno, vitaminas y microelementos de la pulpa de naranja, hacen que este sustrato sea una buena fuente para los requerimientos

Cuadro 5. Rapidez con que los formulados base fueron acarreados por las hormigas forrajeras, medida en minutos que tardaron en acarrear toda la muestra al nido.

\begin{tabular}{cc}
\hline Gránulo & $\begin{array}{c}\text { Promedio de tiempo de } \\
\text { acarreo (minutos) }\end{array}$ \\
\hline C1 & $33,53 \mathrm{a}$ \\
C2 & $43,37 \mathrm{a}$ \\
C3 & $47,46 \mathrm{a}$ \\
A1 & $71,38 \mathrm{~b}$ \\
Mirex- $\mathrm{S}_{\circledast}$ & $72,04 \mathrm{~b}$ \\
\hline
\end{tabular}

Prueba LSD Fisher $\alpha=0,05$. Letras distintas indican diferencias significativas. C: formulaciones con citropulpa como atrayente y A con aceite de semillas de naranja; Mirex-S: granulado comercial. Los tratamientos A2 y A3 no fueron acarreados durante tiempo que duró la prueba. 
nutricionales del hongo simbiótico cultivado por las hormigas. Además, ha sido considerado un atrayente con alto potencial para la preparación de cebos para hormigas forrajeras (Boaretto et ál. 2003, Verza et ál. 2006). Por lo tanto se considera que los formulados con las mejores características fueron el A1 con aceite de semillas de naranja y $\mathrm{C} 1$ preparado con citropulpa.

\section{Preferencia de acarreo del formulado (B1 y B2) con extracto alcohólico de cáscaras de naranja como atrayente}

Como se explica en la metodología, debido a escasez del aceite de semillas de naranja en el mercado local, se evaluó la preferencia de acarreo cuando se sustituyó el atrayente por extracto alcohólico de cáscaras de naranja en el formulado A1. Los resultados de la prueba se muestran en el Cuadro 6. Según el análisis de varianza, el tiempo acarreo del formulado B2 con atrayente extracto alcohólico de cáscaras de naranja al 3\% (v/p), fue significativamente diferente (mayor rapidez de acarreo) al formulado con aceite de semillas de naranja (A3), pero no se observó diferencia entre los formulados con extracto alcohólico. Por lo

Cuadro 6. Rapidez con que los formulados base fueron acarreados por las hormigas forrajeras, medida en minutos que tardaron en acarrear toda la muestra al nido.

\begin{tabular}{cc}
\hline Gránulo & $\begin{array}{c}\text { Tiempo de acarreo } \\
\text { (en minutos) }\end{array}$ \\
\hline B2 & $27,15 \mathrm{a}$ \\
B1 & $33,88 \mathrm{ab}$ \\
A3 & $49,03 \mathrm{~b}$ \\
\hline
\end{tabular}

Prueba LSD Fisher $\alpha=0,05$. Letras distintas indican diferencias significativas. Donde A es la formulación que contienen aceite de semillas de naranja como atrayente y B1 y B2 formulados con extracto alcohólico de cáscaras de naranja al $2 \%$ y $3 \%$, respectivamente. El porcentaje se refiere al volumen del atrayente por cada $100 \mathrm{~g}$ del formulado. tanto el granulado B2 fue el mejor en esta prueba (27,15 minutos), incluso cuando se comparara con los resultados del Cuadro 6.

\section{Porcentaje de humedad, acidez, y absorción de humedad en campo de gránulos base formulados con ingredientes activos}

Según el Cuadro 7, los formulados con citropulpa presentan los porcentajes más altos de humedad, lo que sugiere estos deben secarse durante un periodo de tiempo mayor para disminuir la humedad hasta aproximadamente $12 \%$. Sin embargo esto podría afectar los ingredientes activos, por lo que se recomienda reducir la humedad en la citropulpa antes de preparar el formulado. Además, se observó que el porcentaje de humedad no varió en los gránulos durante 9 las semanas a temperatura ambiente, por lo que se deduce que la humedad es bastante estable en los formulados.

El valor promedio de acidez de los gránulos con ingredientes activos presentó valores más altos (Cuadro 7), que el de los formulados base (Cuadro 4), particularmente en los formulados cuyo ingrediente activo fue levadura o Trichoderma spp.; por lo tanto es importante considerar el efecto en el $\mathrm{pH}$ que la incorporación del ingrediente activo produce en el formulado, para mantener valores aceptables para garantizar la estabilidad y viabilidad de los principios activos en los cebos. También se puede observar que con excepción del cebo BN1\%, el pH no presentó variaciones importantes en ninguno de los formulados, después de 9 semanas.

La determinación de absorción de humedad en campo, durante $4 \mathrm{~h}$, mostró que todos los formulados evaluados, excepto el cebo $\mathrm{BN} 1 \%$, presentaron una disminución en la hidratación en las primeras $2 \mathrm{~h}$ y un aumento en las siguientes 2. Sin embargo, el aumento en los porcentajes de humedad de los cebos no fue significativo durante las $4 \mathrm{~h}$ de la prueba, por lo tanto se deduce que mantuvieron estable la humedad (Figura 3). 
Cuadro 7. Porcentaje de humedad y acidez $(\mathrm{pH})$ presente en los gránulos con ingredientes activos, recién preparados y después de 9 semanas a temperatura ambiente.

\begin{tabular}{|c|c|c|c|c|}
\hline \multirow{2}{*}{ Cebos } & \multicolumn{2}{|c|}{$\%$ Humedad promedio } & \multicolumn{2}{|c|}{ Acidez $(\mathrm{pH})$} \\
\hline & Recién preparados & Después de 9 semanas & Recién preparados & Después de 9 semanas \\
\hline BT & 9,00 & 9,90 & 3,3 & 3,0 \\
\hline $\mathrm{B} \operatorname{Tr} 7,01 \times 10^{7}$ & 11,28 & 10,73 & 6,2 & 5,4 \\
\hline $\mathrm{BN} 1 \%$ & 8,92 & 9,78 & 4,7 & 2,9 \\
\hline BL5\% & 13,43 & 11,75 & 5,3 & 5,2 \\
\hline $\mathrm{CT}$ & 20,28 & 18,95 & 4,9 & 4,9 \\
\hline$C \operatorname{Tr} 7,01 \times 10^{7}$ & 21,13 & 23,45 & 5,1 & 4,8 \\
\hline $\mathrm{CN} 1 \%$ & 19,82 & 20,01 & 4,5 & 4,6 \\
\hline CL5\% & 17,37 & 17,23 & 5,2 & 4,7 \\
\hline Mirex- $S_{\mathbb{R}}$ & 11,48 & 13,88 & 4,6 & 4,8 \\
\hline
\end{tabular}

Donde B: formulado con extracto alcohólico de cáscaras de naranja; C: formulado con citropulpa; negativo; Tr: Trichoderma spp.; N: neem; L: levaduras $\left(7,01 \times 10^{7}, 1 \%\right.$ y 5\%: concentraciones respectivas); Mirex-S $\mathrm{S}_{\circledast}$ : granulado comercial y T: testigo sin ingrediente activo.

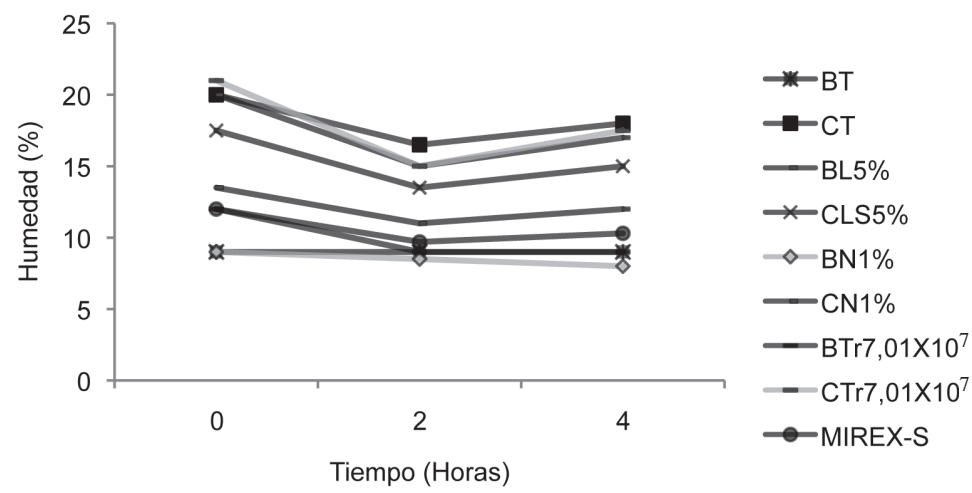

Donde B: formulado con extracto alcohólico de cáscaras de naranja; C: formulado con citropulpa; negativo; Tr: Trichoderma spp.; N: neem; L: levaduras (7,01x107, $1 \%$ y 5\%: concentraciones respectivas); Mirex-S®:granulado comercial y T: testigo sin ingrediente activo.

Fig. 3. Comportamiento en la absorción de humedad de los cebos y los testigos ensayados mediante la prueba de acarreo, determinada por diferencia de peso a $150^{\circ} \mathrm{C}$ medidas a la hora 2 y 4 posteriores de ser colocados en campo (promedio de 3 mediciones en cada tiempo).

\section{Concentración y viabilidad de los microorganismos evaluados como ingredientes activos}

En el Cuadro 8, se observa una diferencia importante entre la concentración de Trichoderma spp., agregada a la fórmula y la concentración medida en los gránulos después de 9 semanas a temperatura ambiente, lo cual se puede explicar como una posible esporulación del hongo durante ese periodo, independiente del formulado base $\left(\mathrm{B} \operatorname{Tr} 7,01 \times 10^{7}\right.$ y $\left.\mathrm{C} \operatorname{Tr} 7,01 \times 10^{7}\right)$, pero también se puede explicar cómo falta de homogeneidad del ingrediente activo en la mezcla, principalmente por ser un proceso artesanal, que debe revisar en futuros trabajos. En cuanto a los tratamientos con levaduras, los resultados muestran que el número de unidades formadoras de colonias (ufc) fue 
Cuadro 8. Concentración conidias y unidades formadoras de colonias en los gránulos formulados con Trichoderma spp., y levaduras colocados a temperatura ambiente 9 semanas.

\begin{tabular}{|c|c|}
\hline Gránulos & cantidad /g \\
\hline $\mathrm{B} \operatorname{Tr} 7,01 \times 10^{7}$ & $8,87 \times 10^{7}$ \\
\hline$C \operatorname{Tr} 7,01 \times 10^{7}$ & $1,02 \times 10^{8}$ \\
\hline BL5\% & $5,68 \times 10^{7}$ \\
\hline CL5\% & $7,71 \times 10^{7}$ \\
\hline
\end{tabular}

Donde B: formulado con extracto alcohólico de cáscaras de naranja; C: formulado con citropulpa; $\mathrm{T}$ : control negativo; Tr: Trichoderma spp.; L: levaduras y 7,01 $\times 10^{7}$ y $5 \%$ : concentraciones del i.a.

menor en el formulado con extracto alcohólico de cáscaras de naranja (BL5\%) en comparación con el formulado con citropulpa (CL5\%) a pesar de que en ambos formulados la concentración del microorganismo fue igual. Este resultado se puede atribuir al atrayente, pero lo recomendable revisar la metodología usada.

La germinación de conidias de Trichoderma spp., varió en los conteos a 24, 48 y 72 . Especialmente, en los gránulos de CTr 7,01 ×107, se observa un aumento en la cantidad de conidias germinadas a las $72 \mathrm{~h}$ después de incubación a $26^{\circ} \mathrm{C}$, mayor incluso al $100 \%$ a la concentración agregada al formulado. Sin embargo, en gránulos de $\mathrm{B} \operatorname{Tr} 7,01 \times 10^{7}$ el número de conidios viables fue inferior $(33,52 \%)$ aunque constante en comparación con el gránulo CTr 7,01 x107 . Sin embargo los resultados muestran que en todas evaluaciones los tiramientos con citropulpa presentaron mayor cantidad de esporas germinadas (Cuadro 9).

Cuadro 9. Conidias germinadas de Trichoderma spp., en los gránulos colocados a temperatura ambiente durante 9 semanas. Conteos a las 24, 48 y $72 \mathrm{~h}$ de incubación a $26^{\circ} \mathrm{C}$.

\begin{tabular}{ccc}
\hline $\begin{array}{c}\text { Tiempo de } \\
\text { incubación } \\
\text { (horas) }\end{array}$ & $\begin{array}{c}\text { Conidias germinadas por gránulos } \\
\mathrm{B} \operatorname{Tr} 7,01 \times 10^{7}\end{array}$ & $\mathrm{C} \operatorname{Tr} 7,01 \times 10^{7}$ \\
\hline 24 & $2,75 \times 10^{6}$ & $2,81 \times 10^{6}$ \\
48 & $3,62 \times 10^{6}$ & $7,45 \times 10^{7}$ \\
72 & $2,35 \times 10^{7}$ & $9,48 \times 10^{7}$ \\
\hline
\end{tabular}

DP= Dato perdido; B: Extracto alcohólico de cáscaras de naranja al 3\%; C: citropulpa; Tr: Trichoderma spp.; 7,01 $\times 10^{7}$ : concentración de conidias en un gramo de formulado.

\section{Preferencia de los gránulos formulados con ingredientes activos}

Según los resultados obtenidos (Cuadro 10) los tiempos de acarreo de los cebos $\mathrm{C} \operatorname{Tr} 2,34 \times 10^{7}$, $\mathrm{C} \operatorname{Tr} 7,01 \times 10^{7}, \mathrm{~B} \operatorname{Tr} 2,34 \times 10^{7}$ y $\mathrm{B} \operatorname{Tr} 7,01 \times 10^{7}$ (con ingrediente activo Trichoderma spp.) son estadísticamente iguales entre si, pero diferentes a la

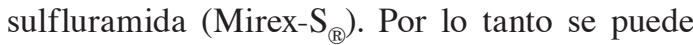
concluir que las hormigas mostraron mayor preferencia por los formulados base (B y C) con Trichoderma spp., que por el granulado comercial, y por lo tanto son una buena alternativa para que cepas de este microorganismo sean transportadas por las hormigas a los nidos.

Cuadro 10. Rapidez con que los cebos con Trichoderma spp., como ingrediente activo fueron acarreados por las hormigas forrajeras, medida en minutos que tardaron en acarrear toda la muestra $(1,00 \mathrm{~g})$ al nido.

\begin{tabular}{cc}
\hline Gránulo & $\begin{array}{c}\text { Promedio de tiempo de acarreo } \\
\text { (minutos) }\end{array}$ \\
\hline $\mathrm{CTr} 2,34 \times 10^{7}$ & $42,72 \mathrm{a}$ \\
$\mathrm{CTr} 7,01 \times 10^{7}$ & $34,80 \mathrm{a}$ \\
$\mathrm{B} T r 2,34 \times 10^{7}$ & $48,09 \mathrm{a}$ \\
$\mathrm{BTr} 7,01 \times 10^{7}$ & $43,09 \mathrm{a}$ \\
$\mathrm{Mirex}^{-\mathrm{S}_{\circledast}}$ & $67,12 \mathrm{~b}$ \\
\hline
\end{tabular}

Medias ajustadas Prueba LSD Fisher $\alpha=0,05$. Letras distintas indican diferencias significativas. Donde B: formulado con extracto alcohólico de cáscaras de naranja; C: formulado con citropulpa; Tr: Trichoderma spp.; $2,34 \times 10^{7}$ y $7,01 \times 10^{7}$ : concentraciones evaluadas.

En cuanto las levaduras como ingrediente activo, las hormigas forrajeras mostraron preferencia (tiempo de acarreo) cuando se uso el extracto alcohólico de cáscaras de naranja como atrayente (BL5\%, BL10\% y BL20\%), independientemente de la concentración de ingrediente activo, los cuales fueron estadísticamente iguales entre sí, pero estadísticamente diferentes (más rápido acarreo) a la sulfluramida (Mirex- $S_{\circledast}$ ). Mientras que en los formulados con citropulpa, la rapidez en el acarreo varió significativamente entre el formulado CL20\% y los formulados CL5\% y CL10\% estos últimos no mostraron diferencias estadísticas 
Cuadro 11. Rapidez con que los cebos con levaduras como ingrediente activo fueron acarreados por las hormigas forrajeras, medida en minutos que tardaron en acarrear toda la muestra $(1,00 \mathrm{~g})$ al nido.

\begin{tabular}{cc}
\hline Gránulo & Promedio de tiempo de acarreo (minutos) \\
\hline CL5\% & $34,15 \mathrm{~b}$ \\
CL10\% & $41,18 \mathrm{ab}$ \\
CL20\% & $55,51 \mathrm{a}$ \\
BL5\% & $23,87 \mathrm{c}$ \\
BL10\% & $24,86 \mathrm{c}$ \\
BL20\% & $24,52 \mathrm{c}$ \\
Mirex-S & $40,31 \mathrm{~b}$ \\
\hline
\end{tabular}

Medias ajustadas. Prueba LSD Fisher $\alpha=0,05$. Letras distintas indican diferencias significativas, Donde B: formulado con extracto alcohólico de cáscaras de naranja; C: formulado con citropulpa; L: levaduras; $5 \%, 10 \%$ y $20 \%$ : concentraciones evaluadas. significativas en comparación con el granulado comercial. El gránulo CL20\% presentó mayor tiempo de acarreo que la sulfluramida y son estadísticamente diferentes (Cuadro 11).

El Cuadro 12 muestra los resultados obtenidos sobre la rapidez de acarreo de los gránulos con extracto de $A$. indica como ingrediente. No se presentaron diferencias estadísticas significativas entre concentraciones del ingrediente activo; sin embargo, todos difieren de la sulfluramida (Mirex- $\left.\mathrm{S}_{\circledast}\right)$, por que fueron más rápidamente acarreados por las hormigas. Por lo tanto se puede concluir que los formulados base evaluados, fueron un buen vehículo para que las hormigas transportaran el neem hacia los nidos.

Cuadro 12. Rapidez con que los cebos con neem (Azadirachta indica) como ingrediente activo fueron acarreados por las hormigas, medida en minutos que tardaron en acarrear toda la muestra $(1,00 \mathrm{~g})$ al nido.

\begin{tabular}{cccc}
\hline Gránulo & $\begin{array}{c}\text { Promedio de tiempo de acarreo } \\
\text { (minutos) }\end{array}$ & Error estándar \\
\hline CN0,4\% & 21,11 & 2,81 & a \\
CN0,6\% & 19,42 & 2,85 & a \\
CN1\% & 22,93 & 2,80 & a \\
BN0,4\% & 19,80 & 2,93 & a \\
BN0,6\% & 20,10 & 2,81 & a \\
BN1\% & 22,50 & 3,00 & b \\
Mirex-S & 40,42 & 3,09 & \\
\hline
\end{tabular}

Medias ajustadas. Prueba LSD Fisher $\alpha=0,05$. Letras distintas indican diferencias significativas. Donde B: formulado con extracto alcohólico de cáscaras de naranja; C: formulado base con citropulpa; N: neem spp., a,i,; 0,4\%, 0,6\% y 1\%: concentraciones evaluadas.

\section{Costo parcial de los gránulos formulados}

Según el análisis de costos parciales, las materias primas necesarias para la formulación de los gránulos son de bajo costo y de fácil adquisición en el mercado local. Además es de esperar que al escalar la producción, los costos asociados a su elaboración tendrían una disminución gracias a que al mayoreo los precios de las materias primas podrían ser menores (Cuadro 13). 
Cuadro 13. Costos parciales de la preparación de un kilogramo de los gránulos formulados de acuerdo con los precios en el mercado (Costa Rica 2009) en dólares americanos por kilogramo o litro de producto.

\begin{tabular}{cc}
\hline Formulado & Costo por kg (US \$) \\
\hline BT & 2,00 \\
CT & 1,24 \\
BTr7,01x107 & 3,09 \\
CTr7,01x10 & 2,33 \\
BL5\% & 2,45 \\
CL5\% & 1,69 \\
BN1\% & 2,20 \\
CN1\% & 1,44 \\
\hline
\end{tabular}

No se incluyen los costos asociados a la mano de obra, ni a los servicios de energía eléctrica y agua. $1 \mathrm{~kg}$ de Mirex- $\mathrm{S}_{\circledast}$ (Sulfluramida) tiene un precio entre $\$ 9,00$ y $\$ 10,00$ (US) en el mercado local.

\section{CONCLUSIONES}

La presente investigación permite concluir que la formula de los gránulos elaborados con citropulpa como atrayente es la más recomendada para que se utilice en investigaciones dirigidas a la búsqueda de ingredientes activos con efecto biológico para el control de hormigas forrajeras del género Atta, debido a su capacidad de atraer a las hormigas y enmascarar los ingredientes activos, la rapidez de acarreo, el menor costo de producción, su estabilidad química y su capacidad de conservar viable los ingredientes activos evaluados en esta investigación. Sin embargo, en regiones donde la citropulpa no está disponible, el extracto alcohólico de naranjas puede ser una opción para la preparación de gránulos con ingredientes activos.

Se puede concluir que la mayoría de los gránulos evaluados presentaron porcentajes de humedad altos. Sin embargo se pudo observar que todos los gránulos conservaron sus características físicas de forma y firmeza durante todo el tiempo de la investigación.

\begin{tabular}{lr}
\hline Precio de materias primas por kg o (US \$) \\
\hline Gelatina & 14,18 \\
Azúcar pulverizada & 1,36 \\
Maicena & 2,45 \\
Talco & 1,64 \\
Bentonita & 2,08 \\
Citropulpa & 0,23 \\
Extracto alcohólico de cáscaras de & 1,12 \\
naranja* & 2,27 \\
Aceite de soya & 0,15 \\
Agua destilada & 9,09 \\
Saf instant (levaduras) & 12,86 \\
Triact 64 EC (extracto de Azadirachta & \\
indica) & 10,91 \\
Trichoderma spp. (1X10 & \\
\hline
\end{tabular}

${ }^{*}$ No se incluye el costo del tiempo de trabajo para su preparación.

\section{LITERATURA CITADA}

ARANGO J., SINIGUI A. 2008. Manejo de la sanidad vegetal en el bosque tropical húmedo: el caso de las hormigas arrieras en Chageradó. Revista de Agroecología, LEISA, Marzo, p. 28-31.

ATSDR (Agencia para Sustancias Tóxicas y el Registro de Enfermedades IT). 1995. Reseña Toxicológica del Mirex y la Clordecona. Departamento de Salud y Servicios Humanos de Estados Unidos. Consultado 5 diciembre 2008. Disponible en http://www.atsdr. cdc.gov/es/toxfaqs/es_tfacts66.html

BOARETTO M., FORTI L. 1997. Perspectivas no controle de formigas cortadeiras. Departamento de Defesa Fitossanitária da FCA/UNESP. Série técnica IPEF. 11(30):31-46.

BOARETTO M., FORTI L., LOPES J., NAGAMOTO N., DE ANDRADE A., MOREIRA A., VIANA A., RAMOS V. 2003. Response of the grass-cutting ant Atta capiguara gonçalves, 1944 (Hymenoptera: Formicidae) to sugars and artificial sweeteners. Scientia Agricola 60(3):505-509.

CAFFARINI P., CARRIZO P., PELICANO A. 2006. Extractos cítricos como atrayentes para cebos hormiguicidas con sustancias naturales. Revista Facultad de Ciencias Agrícolas UNCuyo 38(1):19-26.

CAFFARINIP., CARRIZO P.,PELICANO A., ROGGEROP., PACHECO P. 2008. Efectos de extractos acetónicos y acuosos de Ricinus communis (ricino), Melia 
azedarach (paraíso) y Trichillia glauca (trichillia), sobre la hormiga negra común (Acromyrmex lundi), IDESIA, 26(1):59-64.

CHAPELA I., REHNER S., SCHULTZ T., MUELLER U. 1994. Evolutionary history of the symbiosis between fungus growing ants and their fungi. Science 266:1691-1695.

DELABIE J., DELlA L., PASTRE L. 2000. Protocolo de experimentação para avaliar a atratividade de novas formulações de iscas granuladas utilizadas no controle das formigas cortadeiras Acromyrmex spp., e Atta spp. (Hymenoptera: Formicidae: Myrmicinae: Attini) no Campo Brasil. An. Soc. Entomol. Brasil 29(4):843-848.

DI RIENZO J., CASANOVES F., BALZARINI M., GONZÁLEZ L., TABLADA M., ROBLEDO C. 2009. InfoStat versión 2009. Grupo InfoStat, FCA, Universidad Nacional de Córdoba, Argentina.

GRUBER A., VALDIX J. 2003. Control de Atta spp., con prácticas agrícolas e insecticidas botánicos. Manejo Integrado de Plagas y Agroecología 67:87-90.

HINKLE G., WETTERER J., SCHULTZ T., SOGIN M. 1994. Phylogeny of the attine fungi based on analysis of small subunit ribosomal RNA gene sequences. Science 266:1695-97.

HÖLLDOBLER B., WILSON E. 1999. The ants. The Belknap press of Harvard University Press, Cambridge, Massachussetts. 732 p.

KUMAR H., PATOLE M., SHOUCHE Y. 2006. Fungal farming: a story of four partner evolution. Current Science 90(11):1463-1464.

LÓPEZ E., ORDUZ S. 2003. Metarhizium anisopliae y Trichoderma viride controlan colonias de Atta cephalotes en campo mejor que un insecticida químico. Unidad de Biotecnología y Control Biológico, Corporación para Investigaciones Biológicas-CIB, Medellín, Colombia. Consultado 23 noviembre 2008. Disponible en http://www. revistas.unal.edu.co/index.php/biotecnologia/article/ viewFile/30093/30287

MAZARIEGOS L.A. 2003. Production of biopesticides by the columbian company Laverlam, pp. 111-115. In: U. Roettger and R. Muschler (eds.). International symposium on biopesticides for developing countries (2003: Turrialba, Costa Rica). PAN, GTZ, CATIE.

NACCARATA V., JAFFE K. 1989. Formulación y desarrollo de un cebo atractivo tóxico para control de bachacos, Atta spp. (Hymenoptera: Formicidae) en Venezuela. Boletín de Entomología de Venezuela 5(11):81-88.

OMS-FAO (Organización Mundial de la Salud-Organización de las Naciones Unidas para la Agricultura y la Alimentación IT). 2004. Manual sobre elaboración y empleo de las especificaciones de la FAO y de la OMS para plaguicidas, FAO, IT. 271 p.

ORTIZ A., ORDUZ S. 2000. In vitro evaluation of Trichoderma and Gliocladium antagonism against the symbiotic fungus of the leaf-cutting ant Atta cephalotes. Mycopathologia 150:53-60.

PALACIOS F., GLADSTONE S. 2003. Eficacia del farnesol y de un extracto de semilla de ayote como repelentes de Atta mexicana. Manejo Integrado de Plagas y Agroecología 68:89-91.

PARIONA N., CASTELLANOS P., LEÓN E. 2007. Capacidad entomocida de cepas nativas de Beauveria sp., sobre Schistocerca piceifrons peruviana (Lynch Arribalzaga 1903). Revista Peruana de Biología 14(2):253-257.

PÉREZ R. 1947. El problema de las hormigas del género Atta Fabr., en la América. Tesis de maestría, Instituto Interamericano de Ciencias Agrícolas, Turrialba, Costa Rica. 74 p.

RICCI M., BENÍTEZ D., PADIN S., MACEIRAS A. 2005. Hormigas argentinas: comportamiento, distribución y control. Facultad de Ciencias Agrarias y Forestales. Universidad Nacional de La Plata, Argentina. 27 p.

VARÓN E. 2006. Distribution and foraging by the leafcutting ant, Atta cephalotes L., in coffee plantations with different types of management and landscape contexts, and alternatives to insecticides for its control. Tesis PhD, University of Idaho, Idaho, US. $145 \mathrm{p}$.

VERZA S., FORTI L., MATOS C., GARCIA M., NAGAMOTO N. 2006. Attractiveness of citrus pulp and orange albedo extracts to Atta sexdens rubropilosa (Hymenoptera: Formicidae). Sociobiology 47(2):391-399.

Todos los derechos reservados. Universidad de Costa Rica. Este artículo se encuentra licenciado con Creative Commons Reconocimiento-NoComercial-SinObraDerivada 3.0 Costa Rica. Para mayor información escribir a rac.cia@ucr.ac.cr 
